\title{
Should sublobar resection be offered for screening-detected lung nodules?
}

\author{
Alan D. L. Sihoe ${ }^{1,2}$ \\ ${ }^{1}$ Gleneagles Hong Kong Hospital, Hong Kong, China; ${ }^{2}$ International Medical Centre, Hong Kong, China \\ Correspondence to: Alan D. L. Sihoe. 27th floor, International Medical Centre, 22 Des Voeux Road Central, Hong Kong, China. \\ Email: asihoe@gmail.com.
}

\begin{abstract}
The increasing use of low-dose CT for screening for lung cancer will inevitably identify many small, asymptomatic lung nodules and ground-glass opacities (GGOs). Current guidelines for the management of screening-detected lesions tend to advise a conservative approach based on serial imaging and intervention only if 'suspicious' features emerge. However, more recent developments in thoracic surgery and in the understanding of the screening-detected lesions themselves prompt some pertinent questions over this conservatism. Is CT surveillance sufficiently reliable to exclude malignancy? Is it really necessary to hold back on operative biopsy and resection given modern surgical safety and efficacy? Is the option for early surgical therapy a viable one-especially with the availability of sublobar resection today? Modern data suggests that the risk of inaction for some screening-detected lesions may be higher than expected, whereas the potential harm of surgical intervention may be substantially reduced by sublobar resection and the latest minimally invasive surgical techniques. A more pro-active approach towards offering surgery for screeningdetected lesions should now be considered.
\end{abstract}

Keywords: Ground-glass opacity (GGO); lung cancer; screening; sublobar; video-assisted thoracic surgery (VATS)

Submitted Feb 07, 2020. Accepted for publication Feb 26, 2020.

doi: $10.21037 /$ tlcr.2020.04.06

View this article at: http://dx.doi.org/10.21037/tlcr.2020.04.06

\section{Lung cancer screening: the promise and the challenge}

Despite the massive progress made with target therapy, immunotherapy and modern variations of radiotherapy, there is still only one realistic hope of cure for the vast majority of patients with lung cancer: surgical resection of early stage disease (1). Modern lung resection surgery—coupled with a complete lymph node dissection-is capable of yielding 5 -year recurrence-free survival rates of over $80 \%$ for patients with stage I disease $(2,3)$. However, the crucial factor for good survival is that the disease must be at an early stage, and it has for years been a challenge to diagnose lung cancer in its early stages because patients tend to be asymptomatic (4).

In recent years, low-dose computed tomography (LDCT) of the thorax has emerged as a viable tool for lung cancer screening in asymptomatic adults (5-9). LDCT has been proven in large randomized trials to both increase the rate of early stage detection of lung cancer and to reduce the mortality of this disease $(5,8,9)$. More than any improvement in pharmaceutical or surgical therapy, this screening has the greatest current potential to save countless patients from dying of lung cancer.

The flip-side of the coin, some would argue, is that widespread use of LDCT screening will inevitably detect many small lung lesions that may mimic lung cancer but are actually benign $(10,11)$. These small lesions include both solid nodules, and also ground-glass opacities (GGOs) defined as any hazy lung opacities on CT scan that do not obscure the underlying bronchial structures or pulmonary vessels $(12,13)$. While many may be benign, a proportion actually do represent malignancy, and hence the clinician must decide on how to manage these screening-detected lesions to exclude cancer. This quandary may possibly result in 'over-diagnosis', 'over-investigation', and even 'over-treatment' (14-16). These rather sensationalist terms are frequently used to argue in favor of conservative 
management, but the pragmatic consideration must be to weigh the costs of action versus the risks of inaction.

\section{What do current guidelines say?}

A number of guidelines have been published in recent years by authoritative bodies to help clinicians in managing screening-detected lung nodules and GGOs (17-22). This author has previously reviewed these in a previous article (11). It is noted that essentially all current guidelines for LDCT detected lesions share some common features:

(I) The initial management is invariably further imaging;

(II) The type of and interval until that further imaging depends solely on the number, size and solidity of the lesion(s) seen on the initial CT/LDCT;

(III) On follow-up imaging, further investigation is recommended only if a lesion is unchanged or growing in size and is deemed 'suspicious' for malignancy radiologically;

(IV) That further investigation may consist of further follow-up imaging, non-surgical biopsy or 'surgical excision'. The guidelines generally do not suggest any preference of any one of these over the others;

(V) No specific advice is given regarding what 'surgical excision' should entail.

Overall, the current guidelines therefore favor a very conservative approach. The first instinct should be for watchful waiting and offering as little intervention as possible. Even when intervention is required, there appears to be a general reluctance to recommend surgery outright. This is reasonable given that these guidelines were constructed based on clinical data showing that the majority of these small screening-detected lesions tend to be benign (19-22).

However, as this author has pointed out in the previous review, the clinical data on which these guidelines are based were reported from a number of years ago (11). Since then, much progress has been made in thoracic surgery that is pertinent to the management of such small screeningdetected nodules and GGOs. These include newer minimally invasive surgical approaches and sublobar resections (23-25), which promise to reduce the morbidity from the surgery. Greater understanding of the natural history of these screening-detected lesions are also revealing that a more nuanced approach may be required in different populations around the world $(26,27)$. The risk of malignancy may actually be greater than previously estimated in some parts of the world $(27,28)$. In other words, the costs of action are reducing while the risks of inaction may be higher than expected. In view of this, three important questions have emerged for clinicians to seriously contemplate.

\section{"Why are we just relying on imaging for initial management?"}

The guidelines recommend follow-up imaging-usually $\mathrm{CT}$ - as initial management in most cases of screeningdetected lung lesions. This is based on two assumptions: (I) that the initially detected lesions are most likely benign; and (II) that follow-up LDCT or CT can safely identify which lesions are 'suspicious' for malignancy that warrant further investigation. The first assumption is based on previously published data from multiple studies (usually retrospective) that suggest that $10 \%$ to $43 \%$ of screening-detected lung lesions are 'false positives' $(22,29)$. In the well-known National Lung Screening Trial (NLST), the false positive rate with LDCT was reported to be $23.5 \%$, with these mostly due to intrapulmonary benign lymph nodes and noncalcified granulomas (5). Even amongst the lung cancers found in the NLST, it was estimated that $18 \%$ were indolent tumors and were hence cases of 'over-diagnosis' (30). The second assumption is that on follow-up CT, some lesions may disappear while those that are stable or growing have higher risk of being malignant $(12,19,22)$.

The problem with these assumptions is that CT differentiation between benign and malignant lesions is never fully reliable. Multiple studies have confirmed that CT alone can never exclude malignancy with absolute accuracy $(11,19,20,22)$. In one study on the use of CT to estimate the presence of invasive cancer in small adenocarcinoma lesions of more than $5 \mathrm{~mm}$, a sensitivity of $78 \%$ and specificity of $58 \%$ was reported (31). In 2016, Hattori and colleagues further demonstrated that the use of size and solidity to determine prognosis-as favored by the guidelinesis invalid for all lesions other than the completely solid ones (32). More alarmingly, a study by Lee and colleagues looked at the use of CT features to distinguish invasive and pre-invasive pathologies in GGOs, and found that even experienced radiologists could not consistently reach an agreement on whether any particular lesion was malignant or not (33). External validation of prediction models based on CT find that these generally offer area under the receiver operating characteristic curve values of 0.73 to 0.90 (34). These findings all suggest that by relying on imaging follow-up only based on initial CT findings, there will always be a possibility of missing some truly malignant 
tumors. The same concerns also hold true for the use of follow-up imaging alone. In the guidelines issued by the British Thoracic Society (BTS), the authors themselves acknowledge that there is "no growth rate threshold beneath which, nor duration of radiological stability beyond which, malignancy is definitely excluded" (20).

Another emerging concern is that the risk of malignancy in screening-detected lung nodules may not be as low as assumed. Studies from North America suggest that the risk of malignancy in such nodules may range from 3.7\% to $23 \%(35,36)$. However, other studies from East Asia report that $53 \%$ to $75 \%$ of resected pulmonary nodules were malignant $(37,38)$. This suggests that disease patterns may vary in different parts of the world, and that guidelines recommending a conservative approach may not be globally applicable. Adenocarcinoma, for example, may be especially prevalent in East Asia $(2,3,27,28,37)$.

Clearly, the reassurance that initial and follow-up CT alone can absolutely preclude further investigation is a shaky if not false one. Even if the risk of malignancy on a screening-detected lesion is considered 'low', the cost of failure to investigate or intervene could be the progression of a malignant tumor to an advanced or incurable stage.

\section{"Why are we avoiding surgery for diagnosis?"}

The guidelines only recommend investigation of screeningdetected lung nodules or GGOs when they persist or grow on follow-up imaging. However, regarding the nature of this investigation, the guidelines are non-specific and noncommittal. The options include further CT surveillance, non-surgical biopsy, or 'surgical excision' (17-22).

The limitations of further CT surveillance have been discussed above. Regarding non-surgical biopsy, today there are a number of techniques available. These include conventional bronchoscopy, percutaneous imaging-guided biopsy, and different systems of navigation bronchoscopy $(39,40)$. Conventional bronchoscopy-even with fluoroscopy-guidance-has a sensitivity for identifying malignant nodules of $5 \%$ to $76 \%(41,42)$, with the figure for benign diagnosis even lower. Newer techniques of endobronchial ultrasound (EBUS), electromagnetic navigation bronchoscopy (ENB), and virtual bronchoscopy navigation (VBN) are said to give similar or higher diagnostic yields $(39,40)$. However, the accumulated volume of experience with these is still not huge, and the probability that publication bias exists skewing reports towards the positive side cannot be ruled out. Ultimately, most screening-detected lesions tend to be away from central airways, and hence a percutaneous approach if favored (19). It has been estimated that the sensitivity of CT-guided transthoracic needle biopsy (TTNB) for identifying malignancy in lung nodules was $90 \%$ or greater $(19,41)$. However, the frequency of non-diagnostic results with TTNB has been reported to be as high as $55 \%(19,41)$. For GGOs $2 \mathrm{~cm}$ or smaller, the sensitivity of TTNB has been reported to be only $50-51 \%(43,44)$. At the same time, $33 \%$ of patients receiving TTNB may experience a pneumothorax, with over a third of those requiring a chest drain insertion (43). Even the bronchoscopic techniques may incur a pneumothorax risk of $1.6 \%$ to $7.5 \%(19,39,41)$.

Despite the imperfect diagnostic yields and the definite risk of minor complications, the guidelines still rank these non-surgical biopsy modalities on an equal footing with surgical excision. For example, the American College of Chest Physicians (ACCP) guidelines note that surgery is "the gold standard for diagnosis", and warn of the "imperfect sensitivity and limited negative predictive value" of TTNB (19). However, it still does not recommend surgery over nonsurgical methods due to considerations of 'surgical risk'. Indeed, the ACCP lists one condition for surgery as "when nonsurgical biopsy is suspicious for malignancy" (19), clearly placing surgery behind non-surgical biopsy. The concerns about surgery are based on the evidence reviewed by the ACCP, which suggest a nonfatal complications rate of about $5 \%$ for diagnostic wedge resection using videoassisted thoracic surgery (VATS) $(45,46)$. Should surgery progress to a lobectomy, the ACCP quoted North American databases showing a mortality rate of $2 \%$ to $3.4 \%(47,48)$. In the review for the BTS guidelines, an inpatient mortality rate of $0.4 \%$ was noted for wedge resection/segmentectomy in the UK, rising to a 90 -day mortality of $4.2 \%(20,49)$. In writing their lung cancer screening guidelines, the National Comprehensive Cancer Network (NCCN) considered that the average mortality rate for major lung surgery in the USA was $5 \%$, and the risk of serious complications was over $20 \%(22,50)$. Given these figures, it is understandable that the current guidelines are reluctant to give stronger recommendations for surgery.

However, the reality is that thoracic surgery has progressed significantly in recent years. The actual 30-day mortality rate from major lung cancer surgery is now only $0.48 \%$ in Japan (51). In ultra-high-volume centers (UHVCs) now emerging in China, the peri-operative mortality of thoracic surgery is now less than $0.1 \%(52,53)$. Mortality and significant morbidity from lesser wedge resections 
are almost non-existent amongst normal-risk patients nowadays. On top of this, minimally invasive thoracic surgery has evolved beyond conventional VATS and robotassisted thoracic surgery (RATS) (23). Modern approaches such as uniportal VATS have become established which promise even less morbidity than ever before $(25,54)$. These techniques can be coupled with modern strategies of enhanced recovery after surgery (ERAS) to further improve patient outcomes post-operative (55-57). Altogether, these advances mean that surgery can be performed with morbidity rates that are significantly lower than those considered by the guidelines, and which are not much more than what can be expected from non-surgical biopsy (58).

In return, surgery gives a much higher diagnostic yield than non-surgical biopsy (59). If a wedge resection is performed, the specificity should in theory be $100 \%$. More importantly, surgical biopsy can be performed with intra-operative frozen section (60). This can give a diagnostic accuracy of up to $97 \%$ for small peripheral invasive adenocarcinoma. The importance of this is that if such malignant pathology exists, the surgeon can proceed immediately in the same operation to a curative resection. This significantly reduces the interval between initial presentation and final treatment for each patient, which in turn may potentially improve survival (61). It is therefore disappointing that current guidelines do not even mention the feasibility of combining diagnosis and therapy using surgery in this way for screening-detected lesions.

\section{"Why are we giving up on the golden opportunity for surgical treatment?"}

That surgery can provide both diagnosis and treatment are worthy of further consideration. Screening-detected lung nodules and GGOs tend to be small (5-8). In the NLST, $40 \%$ of the cancers found by CT were stage IA (5). In the European NELSON trial of lung cancer screening, that figure is closer to $50 \%$ (8). The significance of these observations is that many screening-detected lung lesions are therefore amenable to sublobar resection.

For many years, sublobar resection was almost taboo for lung cancer therapy. This largely was a result of the Lung Cancer Study Group's randomized trial in 1995 which concluded that sublobar resection resulted in significantly worse survival and a higher local recurrence rate than lobectomy for T1N0 lung cancer (62). However, oncologic outcomes with sublobar resection have substantially improved since then, and modern results show no difference in survival compared to lobectomy for tumors at $2 \mathrm{~cm}$ diameter or smaller (63). The keys to good outcomes have also been well delineated now: (I) stage IA disease with a tumor diameter of $2 \mathrm{~cm}$ or smaller; (II) a higher consolidation: tumor ratio on CT for GGO; (III) achieving a wide resection margin (at least $1 \mathrm{~cm}$ or more); and (IV) adequate nodal dissection (24). In addition, anatomical segmentectomy tends to give better survival than wedge resection-perhaps because of the greater resection margins usually obtained with the former (64). Because screening detected lung nodules and GGOs frequently all these criteria for good survival, they are ideal for sublobar resection with curative intent. Indeed, the rate of performing segmentectomy has seen a marked increase in recent years, particularly in East Asia $(52,53)$.

The advantage of sublobar resection is of course that minimizing the lung volume resected should in turn minimize the harm and morbidity caused to the patient. A good volume of evidence has been published demonstrating that compared to lobectomy a sublobar resection can better preserve lung function (in terms of spirometry results, pulmonary gas exchange, anaerobic threshold, and so on), and also reduce post-operative morbidity $(62,65-67)$. This is especially important in elderly and frail patients who may not tolerate a lobectomy $(68,69)$. The ACCP recommends that in considering surgery for lung cancer: "In patients with major increased risk or perioperative mortality... (due to age related or other co-morbidities), an anatomic sublobar resection (segmentectomy) over a lobectomy is suggested." (1). In normal risk patients, 'elective' sublobar resection can also be considered (24). As discussed above, current clinical evidence confirms that in well-selected patients, elective sublobar resection does not compromise oncological outcomes compared to lobectomy. At the time of this writing, large randomized trials comparing sublobar resection versus lobectomy for small lung cancers have been conducted in the USA and Japan respectively and their final findings are eagerly awaited (70,71). However, it is also expected that their conclusions are likely to only confirm what we already know: that elective sublobar resection is a viable alternative to lobectomy in those selected patients with small tumors. The value of the randomized trials may be in ushering elective sublobar resection into current guidelines in the same way as sublobar resection for high risk patients.

Of course, sublobar resection is not the only option available for the treatment of screening-detected nodules once they are diagnosed to be lung cancer. For patients 
with these lesions, another choice would be advanced radiotherapy techniques including stereotactic body radiotherapy (SBRT) and the newer proton beam therapy (72-74). At first glance, the ability to effect potentially curative therapy using SBRT without making a single incision should be very attractive to patients. Reports from the radio-therapy literature point to promising treatment results for SBRT that compare favorably with surgery at 1 -year follow-up (72,74). However, careful scrutiny of the current clinical evidence shows that sublobar resection remains a better option for several reasons. First, many patients receiving SBRT did not actually have a biopsyconfirmed cancer-and this would skew results towards better observed 'survival' (75). Second, if non-surgical biopsy is performed before the SBRT, then the morbidity from the biopsy (as discussed above) needs to be added to that of the SBRT (76), and the combined risk to the patient may not be less than that of surgery. Third, on follow-up for longer periods, multiple studies have confirmed that the survival following sublobar surgery is superior to that following SBRT in the medium- to long-term (77-80). Fourth, the assumption that SBRT causes less harm than sublobar surgery may be false. In an elegant study by Crabtree and colleagues, patients receiving SBRT, sublobar resection and radio-frequency ablation were compared (81). Despite patients in the sublobar group having significantly worse pre-treatment lung function, they did not experience more post-treatment adverse events than those in the other study arms. In this context, it would appear that for patients with screening-detected lung nodules, sublobar surgery offers potentially better diagnosis, better cure and no added morbidity compared to the alternative of SBRT with or without non-surgical biopsy.

\section{A stitch in time saves nine}

Reviewing the development of minimally invasive surgery (MIS) for lung cancer since the 1990s, Prof. Chen Haiquan of Shanghai has espoused the idea of "MIS 3.0" (28). It is clear that the first phase (MIS 1.0) was the reduction of surgical access trauma from open thoracotomy to VATS and its evolutions, such as uniportal VATS and RATS. In more recent years, a trend has emerged for reducing the extent of the resection itself (MIS 2.0) by offering effective sublobar resection to selected patients as discussed above. The next phase of this progression-MIS 3.0-would seek to minimize the overall harm of the disease and the surgery to the patient through better strategizing. This could be effected in a variety of ways, including streamlining surgery to reduce overall operating times or developing effective peri-operative management pathways (such as enhanced recovery after surgery programmes) $(28,56,57)$.

In the context of screening-detected lung nodules and GGOs, this concept of MIS 3.0 could be applied to managing the patient over the course of his or her lifetime. According the current guidelines, any screening-detected lesion is followed up with repeated imaging, involving cost and radiation exposure to the patient repeatedly. Should any change or persistence be noted on follow-up, non-surgical biopsy may be performed which incurs a certain morbidity risk. Because of the inherent limitations in their diagnostic accuracy, such non-surgical biopsies may even have to be repeated, multiplying the risk of morbidity. At this time, if malignancy is ultimately confirmed, major resectionsuch as lobectomy-may have to be considered because of the interval progression of the lesion which prompted the biopsy. Generally, lobectomy for early stage lung cancer carries a mortality risk of $0.5-3.0 \%$, and provides a 5 -year survival of around $70-80 \%(20,22,74)$. During follow-up with imaging or investigation of a persistent/growing lesion, a small proportion of patients may even be found to have more advanced inoperable disease, or they may be found to be unsuitable for the required lobectomy-thereby losing any realistic chance at 'cure'.

The MIS 3.0 alternative would be to consider a more pro-active approach to screening-detected lung nodules and GGOs that steers away from the guidelines. At the individual level, certain screening-detected lesions may be higher risk for malignancy-for example, the risk of adenocarcinoma in younger, non-smoking females in East Asia is recognized to be higher $(2,3,27,28)$. Pursuing an agenda of individualized care, if the cancer risk is deemed high and the operative risk low, it is not unreasonable to consider upfront surgery. VATS - perhaps uniportal VATS with pre-operative lesion localization-can be performed, removing the lesion very simply by sublobar resection. The lesion is analyzed by intra-operative frozen section, and surgical biopsy in this way has superior accuracy to any nonsurgical modality. If the lesion is benign, the operation is concluded and the risk of intervention-related morbidity is nowadays very low (not necessarily higher than non-surgical biopsy). The patient is spared the mental stress and anxiety of carrying an indeterminate lung lesion for months or years, and the exposure to repeated imaging and investigations. If the lesion is found to be malignant, immediate surgical therapy can be given in the same operation. Because the 
lesion is likely to be small at this time, many if not most cases may even be amenable to curative therapy by sublobar resection alone. The risk of mortality and morbidity is less than if a lobectomy were performed later when the lesion has progressed. More importantly, the disease is more likely to be in its earliest stage, and hence the survival is better after surgery. If the lesion is pre-malignant, the survival with a minimally invasive sublobar resection can reach virtually $100 \%$. This contrasts with waiting until a lesion becomes larger, when the lobectomy is more traumatic and has lower chance of 'cure'.

The old saying 'a stitch in time saves nine' may sound indecipherable to those who are not native English speakers. It basically means: if there is a tear in your dress then you can either repair it now with just one stitch, or wait until the tear becomes big-by which time you will need nine stitches to repair it. This is perhaps exactly the consideration that clinicians should make with screeningdetected lung lesions.

\section{Conclusions}

As screening becomes more widely used, clinicians will face more and more screening-detected nodules being discovered. Current guidelines advocate a conservative approach, predicated on the assumptions that most lesions are benign and that intervention (surgery) carries high risks. However, there is emerging understanding that the risk of malignancy in screening-detected lesions may actually be higher than assumed, especially in certain parts of the world. Progress with surgery has also meant that the risk of morbidity is now very low-especially with modern MIS approaches and the availability of sublobar surgery. If the risk of inaction is higher than anticipated, and the cost of surgery is lower than ever before, it is time to consider whether a more pro-active strategy should now be considered.

\section{Acknowledgments}

Funding: None.

\section{Footnote}

Provenance and Peer Review: This article was commissioned by the Guest Editors (Paul Van Schil and Annemiek Snoeckx) for the series "Lung cancer screening" published in Translational Lung Cancer Research. The article has undergone external peer review.
Conflicts of Interest: The author has completed the ICMJE uniform disclosure form (available at http://dx.doi. org/10.21037/tlcr.2020.04.06). The series "Lung cancer screening" was commissioned by the editorial office without any funding or sponsorship. The author has no other conflicts of interest to declare.

Ethical Statement: The author is accountable for all aspects of the work in ensuring that questions related to the accuracy or integrity of any part of the work are appropriately investigated and resolved.

Open Access Statement: This is an Open Access article distributed in accordance with the Creative Commons Attribution-NonCommercial-NoDerivs 4.0 International License (CC BY-NC-ND 4.0), which permits the noncommercial replication and distribution of the article with the strict proviso that no changes or edits are made and the original work is properly cited (including links to both the formal publication through the relevant DOI and the license). See: https://creativecommons.org/licenses/by-nc-nd/4.0/.

\section{References}

1. Howington JA, Blum MG, Chang AC, et al. Treatment of stage I and II non-small cell lung cancer: Diagnosis and management of lung cancer, 3rd ed: American College of Chest Physicians evidence-based clinical practice guidelines. Chest 2013;143:e278S-313S.

2. Sawabata N. Prognosis of lung cancer patients in Japan according to data from the Japanese Joint Committee of Lung Cancer Registry. Respir Investig 2014;52:317-21.

3. Liang $\mathrm{W}$, Shao $\mathrm{W}$, Jiang $\mathrm{G}$, et al. Chinese multi-institutional registry (CMIR) for resected non-small cell lung cancer: survival analysis of 5,853 cases. J Thorac Dis 2013;5:726-9.

4. Zhou Q, Fan $\mathrm{Y}, \mathrm{Wu} \mathrm{N}$, et al. Demonstration program of population-based lung cancer screening in China: Rationale and study design. Thorac Cancer 2014;5:197-203.

5. Aberle DR, Adams AM, Berg CD, et al. Reduced lungcancer mortality with low-dose computed tomographic screening. N Engl J Med 2011;365:395-409.

6. Zhao SJ, Wu N. Early detection of lung cancer: Lowdose computed tomography screening in China. Thoracic Cancer 2015;6:385-9.

7. Nawa T, Nakagawa T, Mizoue T, et al. Low-dose Computed Tomography Screening in Japan. J Thorac Imaging 2015;30:108-14.

8. de Koning HJ, van der Aalst CM, de Jong PA, et al. 
Reduced lung-cancer mortality with volume CT screening in a randomized trial. $\mathrm{N}$ Engl J Med 2020;382:503-13.

9. Yu SWY, Leung CS, Tsz CH, et al. Does low-dose computed tomography screening improve lung cancerrelated outcomes? - a systematic review. Video-assist Thorac Surg 2020. doi: http://dx.doi.org/10.21037/ vats.2020.01.02.

10. Pedersen JH, Saghir Z, Winkler Wille MM, et al. Groundglass opacity lung nodules in the era of lung cancer CT screening: radiology, pathology, and clinical management. Oncology (Williston Park) 2016;30:266-74.

11. Sihoe AD, Cardillo G. Solitary pulmonary groundglass opacity: is it time for new surgical guidelines? Eur J Cardiothorac Surg 2017;52:848-51.

12. Chang B, Hwang J, Choi Y, et al. Natural History Of Pure Ground-Glass Opacity Lung Nodules Detected By LowDose Ct Scan. Chest 2013;143:172-8.

13. Aoki T. Growth of pure ground-glass lung nodule detected at computed tomography. J Thorac Dis 2015;7:E326-8.

14. Kobayashi Y, Mitsudomi T. Management of ground-glass opacities: should all pulmonary lesions with ground-glass opacity be surgically resected? Transl Lung Cancer Res 2013;2:354-63.

15. Detterbeck FC. Overdiagnosis during lung cancer screening: is it an overemphasised, underappreciated, or tangential issue? Thorax 2014;69:407-8.

16. Heleno B, Siersma V, Brodersen J. Estimation of Overdiagnosis of Lung Cancer in Low-Dose Computed Tomography Screening: A Secondary Analysis of the Danish Lung Cancer Screening Trial. JAMA Intern Med 2018;178:1420-2.

17. Jaklitsch MT, Jacobson FL, Austin JH, et al. The American Association for Thoracic Surgery guidelines for lung cancer screening using low-dose computed tomography scans for lung cancer survivors and other high-risk groups. J Thorac Cardiovasc Surg 2012;144:33-8.

18. Japanese Society for CT Screening. Guidelines for the management of pulmonary nodules detected by low-dose CT lung cancer screening version 3. Available online: http://www.jscts.org/pdf/guideline/gls3rd_english130621. pdf. Accessed 3 Feb 2020.

19. Gould MK, Donington J, Lynch WR, et al. Evaluation of individuals with pulmonary nodules: when is it lung cancer? Diagnosis and management of lung cancer, 3rd ed: American College of Chest Physicians evidence-based clinical practice guidelines. Chest 2013;143:e93S-120S.

20. Callister ME, Baldwin DR, Akram AR, et al. British Thoracic Society guidelines for the investigation and management of pulmonary nodules. Thorax 2015;70 Suppl 2:ii1-ii54.

21. MacMahon H, Naidich DP, Goo JM, et al. Guidelines for Management of Incidental Pulmonary Nodules Detected on CT Images: From the Fleischner Society 2017. Radiology 2017;284:228-43.

22. National Comprehensive Cancer Network (NCCN) Clinical Practice Guidelines in Oncology. Lung Cancer Screening Version 1.2020. Available online: https://www. nccn.org/professionals/physician_gls/pdf/lung_screening. pdf. Accessed 3 Feb 2020.

23. Sihoe ADL. The evolution of minimally invasive thoracic surgery: implications for the practice of uniportal thoracoscopic surgery. J Thorac Dis 2014;6:S604-17.

24. Sihoe AD, Van Schil P. Non-small cell lung cancer: when to offer sublobar resection. Lung Cancer 2014;86:115-20.

25. Sihoe AD. Uniportal video-assisted thoracic (VATS) lobectomy. Ann Cardiothorac Surg 2016;5:133-44.

26. Samet JM, Avila-Tang E, Boffetta P, et al. Lung cancer in never smokers: clinical epidemiology and environmental risk factors. Clin Cancer Res 2009;15:5626-45.

27. Luo X, Zheng S, Liu Q, et al. Should Nonsmokers Be Excluded from Early Lung Cancer Screening with LowDose Spiral Computed Tomography? Community-Based Practice in Shanghai. Transl Oncol 2017;10:485-90.

28. Zheng D, Chen H. Lung cancer screening in China: earlystage lung cancer and minimally invasive surgery 3.0. J Thorac Dis 2018;10:S1677-9.

29. Croswell JM, Baker SG, Marcus PM, et al. Cumulative incidence of false-positive test results in lung cancer screening: a randomized trial. Ann Intern Med 2010;152:505-12, W176-80.

30. Patz EF Jr, Pinsky P, Gatsonis C, et al. Overdiagnosis in low-dose computed tomography screening for lung cancer. JAMA Intern Med 2014;174:269-74.

31. Wilshire CL, Louie BE, Manning KA, et al. Radiologic Evaluation of Small Lepidic Adenocarcinomas to Guide Decision Making in Surgical Resection. Ann Thorac Surg 2015;100:979-88.

32. Hattori A, Matsunaga T, Takamochi K, et al. Neither Maximum Tumor Size nor Solid Component Size Is Prognostic in Part-Solid Lung Cancer: Impact of Tumor Size Should Be Applied Exclusively to Solid Lung Cancer. Ann Thorac Surg 2016;102:407-15.

33. Lee SM, Park CM, Goo JM, et al. Invasive pulmonary adenocarcinomas versus preinvasive lesions appearing as ground-glass nodules: differentiation by using CT features. Radiology 2013;268:265-73.

34. Gurney JW. Determining the likelihood of malignancy in 
solitary pulmonary nodules with Bayesian analysis. Part I. Theory. Radiology 1993;186:405-13.

35. McWilliams A, Tammemagi MC, Mayo JR, et al. Probability of cancer in pulmonary nodules detected on first screening CT. N Engl J Med 2013;369:910-9.

36. Gould MK, Ananth L, Barnett PG, et al. A clinical model to estimate the pretest probability of lung cancer in patients with solitary pulmonary nodules. Chest 2007;131:383-8.

37. Li Y, Chen KZ, Wang J. Development and validation of a clinical prediction model to estimate the probability of malignancy in solitary pulmonary nodules in Chinese people. Clin Lung Cancer 2011;12:313-9.

38. Yonemori K, Tateishi U, Uno H, et al. Development and validation of diagnostic prediction model for solitary pulmonary nodules. Respirology 2007;12:856-62.

39. Deng CJ, Dai FQ, Qian K, et al. Clinical updates of approaches for biopsy of pulmonary lesions based on systematic review. BMC Pulm Med 2018;18:146.

40. Khan KA, Nardelli P, Jaeger A, et al, Cantillon-Murphy P, Kennedy MP. Navigational Bronchoscopy for Early Lung Cancer: A Road to Therapy. Adv Ther 2016;33:580-96.

41. Schreiber G, McCrory DC. Performance characteristics of different modalities for diagnosis of suspected lung cancer: summary of published evidence. Chest 2003;123:115S-28S.

42. Rivera MP, Mehta AC; American College of Chest Physicians. Initial diagnosis of lung cancer: ACCP evidence-based clinical practice guidelines ( 2 nd edition). Chest 2007;132:131S-48S.

43. Shimizu K, Ikeda N, Tsuboi M, et al. Percutaneous CTguided fi ne needle aspiration for lung cancer smaller than $2 \mathrm{~cm}$ and revealed by ground-glass opacity at CT. Lung Cancer 2006;51:173-9.

44. Hur J, Lee HJ, Nam JE, et al. Diagnostic accuracy of CT fluoroscopy-guided needle aspiration biopsy of groundglass opacity pulmonary lesions. AJR Am J Roentgenol 2009;192:629-34 .

45. Allen MS, Deschamps C, Lee RE, et al. Video-assisted thoracoscopic stapled wedge excision for indeterminate pulmonary nodules. J Thorac Cardiovasc Surg 1993;106:1048-52.

46. Mack MJ, Hazelrigg SR, Landreneau RJ, et al. Thoracoscopy for the diagnosis of the indeterminate solitary pulmonary nodule. Ann Thorac Surg 1993;56:825-30.

47. Boffa DJ, Allen MS, Grab JD, et al. Data from The Society of Thoracic Surgeons General Thoracic Surgery database: the surgical management of primary lung tumors. J Thorac Cardiovasc Surg 2008;135:247-54 .
48. Gopaldas RR, Bakaeen FG, Dao TK, et al. Video-assisted thoracoscopic versus open thoracotomy lobectomy in a cohort of 13,619 patients [published correction appears in Ann Thorac Surg . 2011;92(3):1162]. Ann Thorac Surg 2010;89:1563-70 .

49. Powell HA, Tata LJ, Baldwin DR, et al. Early mortality after surgical resection for lung cancer: an analysis of the English National Lung cancer audit. Thorax 2013;68:826-34.

50. Bach PB, Cramer LD, Schrag D, et al. The influence of hospital volume on survival after resection for lung cancer. N Engl J Med 2001;345:181-8.

51. Masuda M, Okumura M, Doki Y, et al. Thoracic and cardiovascular surgery in Japan during 2014 : Annual report by The Japanese Association for Thoracic Surgery. Gen Thorac Cardiovasc Surg 2016;64:665-97.

52. Yao F, Wang R, Guo X, et al. Annual report of Department of Thoracic Surgery at Shanghai Chest Hospital. Shanghai Chest 2018;2:18. http://dx.doi.org/10.21037/ shc. 2017.10 .03

53. Sihoe ADL, Han B, Yang TY, et al. The Advent of Ultrahigh Volume Thoracic Surgical Centers in Shanghai. World J Surg 2017;41:2758-68.

54. Sihoe ADL. Uniportal Lung Cancer Surgery: State of the Evidence. Ann Thorac Surg 2019;107:962-72.

55. Sihoe AD, Yu PS, Kam TH, et al. Adherence to a Clinical Pathway for Video-Assisted Thoracic Surgery: Predictors and Clinical Importance. Innovations (Phila) 2016;11:179-86.

56. Gao S, Barello S, Chen L, et al. Clinical guidelines on perioperative management strategies for enhanced recovery after lung surgery. Transl Lung Cancer Res 2019;8:1174-87.

57. Krebs ED, Mehaffey JH, Sarosiek BM, et al. Is less really more? Reexamining video-assisted thoracoscopic surgery versus open lobectomy in the setting of an enhanced recovery protocol. J Thorac Cardiovasc Surg 2020;159:284-94. http://dx.doi.org/10.1016/ j.jtcvs.2019.08.036

58. Shi Z, Chen C, Jiang S, et al. Uniportal video-assisted thoracic surgery resection of small ground-glass opacities (GGOs) localized with CT-guided placement of microcoils and palpation. J Thorac Dis 2016;8:1837-40.

59. Sihoe ADL, Yim APC. VATS as a diagnostic tool. In: General Thoracic Surgery. 7th Edition. Philadelphia: Lippincott Williams \& Wilkins, 2009:313-32.

60. Liu S, Wang R, Zhang Y, et al. Precise Diagnosis of Intraoperative Frozen Section Is an Effective Method to Guide Resection Strategy for Peripheral Small-Sized Lung Adenocarcinoma. J Clin Oncol 2016;34:307-13. 
61. Sihoe ADL, Hiranandani R, Wong H, et al. Operating on a Suspicious Lung Mass Without a Pre-operative Tissue Diagnosis: Pros and Cons. Eur J Cardiothorac Surg 2013;44:231-7.

62. Ginsberg RJ, Rubinstein LV. Randomized trial of lobectomy versus limited resection for T1 N0 non-small cell lung cancer. Lung Cancer Study Group. Ann Thorac Surg 1995;60:615-22; discussion 622-3.

63. Yendamuri S, Sharma R, Demmy M, et al. Temporal trends in outcomes following sublobar and lobar resections for small $(\leq 2 \mathrm{~cm})$ non-small cell lung cancers-a surveillance epidemiology end results database analysis. J Surg Res 2013;183:27-32.

64. El-Sherif A, Fernando HC, Santos R, et al. Margin and local recurrence after sublobar resection of non-small cell lung cancer. Ann Surg Oncol 2007;14:2400-5.

65. Keenan RJ, Landreneau RJ, Maley RH Jr, et al. Segmental resection spares pulmonary function in patients with stage I lung cancer. Ann Thorac Surg 2004;78:228-33.

66. Harada H, Okada M, Sakamoto T, et al. Functional advantage after radical segmentectomy versus lobectomy for lung cancer. Ann Thorac Surg 2005;80:2041-5.

67. Sihoe ADL. Surgical management of ground glass opacities of the lung. Surg Pract 2020;24:23-8. http:// dx.doi.org/10.1111/1744-1633.12408

68. Hattori A, Takamochi K, Matsunaga T, et al. Oncological outcomes of sublobar resection for clinical-stage IA high-risk non-small cell lung cancer patients with a radiologically solid appearance on computed tomography. Gen Thorac Cardiovasc Surg 2016;64:18-24.

69. Takahashi N, Sawabata N, Kawamura M, et al. Multicenter prospective study of sublobar resection for c-stage I non-small cell lung cancer patients unable to undergo lobectomy (KLSG-0801): complete republication. Gen Thorac Cardiovasc Surg 2016;64:470-5.

70. Altorki NK, Wang X, Wigle D, et al. Perioperative mortality and morbidity after sublobar versus lobar resection for early-stage non-small-cell lung cancer: post-hoc analysis of an international, randomised, phase 3 trial (CALGB/Alliance 140503). Lancet Respir Med 2018;6:915-24.

71. Nakamura K, Saji H, Nakajima R, et al, A phase III randomized trial of lobectomy versus limited resection for small-sized peripheral non-small cell lung cancer (JCOG0802/WJOG4607L). Jpn J Clin Oncol 2010;40:271-4.

72. Crabtree TD, Puri V, Robinson C, et al. Analysis of first recurrence and survival in patients with stage I non- small cell lung cancer treated with surgical resection or stereotactic radiation therapy. J Thorac Cardiovasc Surg 2014;147:1183-91.

73. Harada H, Murayama S. Proton beam therapy in nonsmall cell lung cancer: state of the art. Lung Cancer (Auckl) 2017;8:141-5.

74. Chi A, Fang W, Sun Y, et al. Comparison of Longterm Survival of Patients With Early-Stage Non-Small Cell Lung Cancer After Surgery vs Stereotactic Body Radiotherapy. JAMA Netw Open 2019;2:e1915724.

75. Berman AT, Jabbour SK, Vachani A, et al. Empiric Radiotherapy for Lung Cancer Collaborative Group multi-institutional evidence-based guidelines for the use of empiric stereotactic body radiation therapy for non-small cell lung cancer without pathologic confirmation. Transl Lung Cancer Res 2019;8:5-14.

76. D'Amico TA. The best that surgery has to offer. J Thorac Cardiovasc Surg 2013;145:699-701.

77. Shirvani SM, Jiang J, Chang JY, et al. Lobectomy, sublobar resection, and stereotactic ablative radiotherapy for earlystage non-small cell lung cancers in the elderly. JAMA Surg 2014;149:1244-53.

78. Puri V, Crabtree TD, Bell JM, et al. Treatment Outcomes in Stage I Lung Cancer: A Comparison of Surgery and Stereotactic Body Radiation Therapy. J Thorac Oncol 2015;10:1776-84.

79. Paul S, Lee PC, Mao J, et al. Long term survival with stereotactic ablative radiotherapy (SABR) versus thoracoscopic sublobar lung resection in elderly people: national population based study with propensity matched comparative analysis. BMJ 2016;354:i3570.

80. Bryant AK, Mundt RC, Sandhu AP, et al. Stereotactic Body Radiation Therapy Versus Surgery for Early Lung Cancer Among US Veterans. Ann Thorac Surg 2018;105:425-31.

81. Crabtree T, Puri V, Timmerman R, et al. Treatment of stage I lung cancer in high-risk and inoperable patients: comparison of prospective clinical trials using stereotactic body radiotherapy (RTOG 0236), sublobar resection (ACOSOG Z4032), and radiofrequency ablation (ACOSOG Z4033). J Thorac Cardiovasc Surg 2013;145:692-9.

Cite this article as: Sihoe ADL. Should sublobar resection be offered for screening-detected lung nodules? Transl Lung Cancer Res 2021;10(5):2418-2426. doi: 10.21037/ tlcr.2020.04.06 